\title{
ANÁLISE DA ACURÁCIA DOS MÉTODOS CINEMÁTICOS DE POSICIONAMENTO GPS EM APLICAÇÕES COSTEIRAS
}

An analysis of the accuracy of GPS kinematics methods in coastal applications

\author{
ELMO LEONARDO XAVIER TANAJURA ${ }^{1}$ \\ CLAUDIA PEREIRA KRUEGER ${ }^{2}$ \\ RODRIGO MIKOSZ GONÇALVES ${ }^{3}$ \\ ${ }^{1}$ Centro de Ciências Exatas e Tecnológicas - CCET \\ Universidade Federal do Acre (UFAC) \\ Rodovia BR 364, Km 04, nº 6637 - Distrito Industrial \\ CEP: 69915-990 - Rio Branco - Acre - Brasil \\ ${ }^{2}$ Curso de Pós-Graduação em Ciências Geodésicas \\ Universidade Federal do Paraná (UFPR) \\ Caixa Postal 19011 - Centro Politécnico - Jardim das Américas \\ CEP: 81531-990 - Curitiba - Paraná - Brasil \\ ${ }^{3}$ Departamento de Engenharia Cartográfica \\ Centro de Tecnologia e Geociências - CTG \\ Universidade Federal de Pernambuco (UFPE) \\ Av. Prof. Moraes Rego, 1235 - Cidade Universitária \\ CEP: 50670-901 - Recife - Pernambuco - Brasil \\ elmo@ufac.br; krueger@ufpr.br; rodrigo.mikosz@gmail.com
}

\begin{abstract}
RESUMO
O NAVSTAR GPS vem sendo aplicado nas mais diversas áreas entre elas encontram-se o ambiente costeiro. Os levantamentos geodésicos podem ser utilizados para estudar as variações posicionais que ocorrem em sistemas costeiros dinâmicos. O presente trabalho tem por objetivo avaliar a acurácia dos métodos cinemáticos de posicionamento GPS em um esporão arenoso localizado na Ilha do Mel, município de Paranaguá, Estado do Paraná, Brasil. Os testes foram realizados com os seguintes métodos de posicionamento geodésico: Absoluto Cinemático (MAC), Relativo Cinemático (MRC) e Diferencial (RTK e DGPS). Uma estação móvel composta por dois receptores GPS foi construída para efetuar simultaneamente a captação de dados e assim analisar os métodos propostos em um único levantamento geodésico. Os resultados mais satisfatórios foram oriundos da
\end{abstract}


solução RTK, apresentando os menores valores para o Erro Médio Quadrático (EMQ), 0,003 m, 0,007 m e 0,149 m nas componentes Norte (N), Este (E) e Altura Geométrica h, respectivamente. Por fim, recomendações da aplicabilidade dos métodos estudados para a área costeira são apresentadas.

Palavras-chave: Posicionamento Geodésico; Método Absoluto Cinemático; Método Relativo Cinemático; RTK; DGPS.

\section{ABSTRACT}

The NAVSTAR GPS has been applied is several fields, the coastal environment being one of them. The geodetic surveys can be used to study the positional variation that happens in dynamic coastal systems. This paper has the main objective of evaluating the accuracy of GPS kinematics positional methods in a specific sedimentary area located in Mel Island, District of Paranaguá, Paraná State, Brazil. The experiments were undertaken with the geodetic positioning methods as follow: Absolute Kinematic, Relative Kinematic, Differential (RTK and DGPS). A rover station composed by two GPS receivers was built for simultaneously collect the data thereby the proposed methods could be analyzed in a single geodetic survey. The best results found in this study was from the RTK solution, presenting the lowest values for the Root Mean Square (RMS) equals $0.003 \mathrm{~m}, 0.007 \mathrm{~m}$ and $0.149 \mathrm{~m}$ for the north component $(\mathrm{N})$, east component $(\mathrm{E})$ and geometrical height $(\mathrm{h})$, respectively. Finally, recommendations for the applicability of the methods used for costal area are presented.

Keywords: Geodesic Positioning; Absolute Kinematic Method; Relative Kinematic Method; RTK; DGPS.

\section{INTRODUÇÃO}

Desde o lançamento do primeiro satélite artificial, o SPUTNIK I, em Outubro de 1957, várias ciências usufruíram dessa nova era que estaria chegando. A Geodésia Espacial por sua vez teve um significativo avanço no que concerne ao posicionamento, que passaria dessa forma a ser realizado por meio de satélites artificiais, a partir do surgimento do NAVSTAR-GPS.

Pela facilidade que o sistema proporciona as operações para com os usuários, os levantamentos geodésicos baseados no posicionamento com GPS atingem as mais variadas aplicações. Dentre algumas, destaca-se as aplicações relacionadas ao monitoramento ambiental, mais especificamente em regiões costeiras.

No Brasil esse tipo de aplicação foi introduzida por KRUEGER (1996), que na ocasião verificou em duas áreas distintas, Mar do Norte (Alemanha) e Ponta do Poço (Brasil), as soluções de alta precisão com a entrada do uso do GPS no ambiente marinho. Desde então, têm-se desenvolvido no litoral do Estado do Paraná alguns levantamentos geodésicos para fins de pesquisas relacionadas ao monitoramento ambiental na região, isso pelo fato dessa faixa litorânea ser caracterizada por possuir áreas com alta vulnerabilidade a processos erosivos. Tais 
problemas decorrem da interferência entre a intensa dinâmica natural e a ocupação inadequada do solo (IBAMA, 2006).

A Ilha do Mel, localizada na parte central do litoral paranaense, tem sido foco de atenção perante o meio acadêmico científico no que diz respeito a fenômenos erosivos que vêm ocorrendo nos últimos anos, mais precisamente na região do Istmo da Ilha e no esporão arenoso da Praia do Farol.

Este trabalho busca a realização de investigações dos métodos cinemáticos de levantamentos GPS efetuados no esporão arenoso da Ilha do Mel, procurando indicar qual(is) método(s) de posicionamento GPS é(são) adequado(s) para o monitoramento costeiro levando em consideração a relação custo/benefício. Os levantamentos GPS foram efetuados simultaneamente empregando-se os métodos: Relativo Cinemático pós-processado (MRC), Absoluto Cinemático (MAC), Diferencial GPS (DGPS), Real Time Kinematic (RTK) em um trecho do esporão arenoso da Ilha.

Os métodos cinemáticos de levantamento se caracterizam pelo fato do receptor incumbido da coleta dos dados estar em pleno movimento, determinando assim as coordenadas de uma trajetória (SEEBER, 2003).

O nível de precisão do método de levantamento cinemático com pósprocessamento é de $10 \mathrm{~cm}$ podendo alcançar poucos centímetros caso as condições sejam favoráveis (cobertura de satélites, ausência de multicaminho, etc) (SEEBER, 2003).

O posicionamento absoluto também conhecido por posicionamento por ponto é caracterizado por utilizar-se de apenas um único receptor no rastreio. A precisão horizontal alcançada por este método de posicionamento era de $100 \mathrm{~m}$ e a precisão vertical era de $156 \mathrm{~m}$, com nível de probabilidade de 95\%, com a técnica de segurança denominada de Disponibilidade Seletiva - SA (Selective Availability) ativada (DIVIS, 2000). Com a SA desativada (02/05/2000) passou-se a obter $13 \mathrm{~m}$ e $25 \mathrm{~m}$, na precisão horizontal e vertical, respectivamente, com nível de probabilidade de 95\% (SEEBER, 2003).

No método DGPS as observações utilizadas para a navegação normalmente são as pseudodistâncias ou as pseudodistâncias filtradas pelas portadoras. Na prática o mais utilizado é o que adota apenas uma pseudodistância. Nesse caso, a precisão atingida é na ordem de 0,5 a 3,0 m dependendo do comprimento da linha de base. (MONICO, 2008). Nesse método pode-se considerar um decréscimo da sua precisão em função do aumento da sua linha de base a uma taxa de aproximadamente $10 \mathrm{ppm}$, ou seja, $1 \mathrm{~cm}$ a cada quilômetro (HOFMANNWELLENHOF et al 1994).

No método de Posicionamento RTK, como as ambigüidades são solucionadas praticamente em tempo real, o usuário tem a sua disponibilidade distâncias entre o receptor e o satélite com precisão da ordem de poucos milímetros, o que permite o posicionamento da ordem de poucos centímetros (MONICO, 2008). 


\section{2. ÁREA DE ESTUDO}

Os levantamentos foram efetuados na Ilha do Mel, município de ParanaguáPR. A localidade encontra-se sob sua jurisdição e proteção ao encargo do Instituto Ambiental do Paraná (IAP) e do Batalhão de Polícia Militar do Paraná. Está localizada na parte central do litoral do Estado do Paraná, na desembocadura do Complexo Estuarino de Paranaguá, ocupando uma área de aproximadamente 2,7620 ha (SEMA, 2004).

A Ilha do Mel está situada a cerca de $4 \mathrm{~km}$ de Pontal do Paraná e a $24 \mathrm{~km}$ de Paranaguá. O acesso se dá pela BR 277 até Paranaguá ou Pontal do Paraná (Rodovias PR 407 e 412), de onde partem os barcos para a Ilha, conforme ilustra a Figura 1. A travessia leva em média 30 minutos a partir de Pontal do Paraná e uma hora e meia de Paranaguá.

Figura 1 - Localização e acessos para a Ilha do Mel.

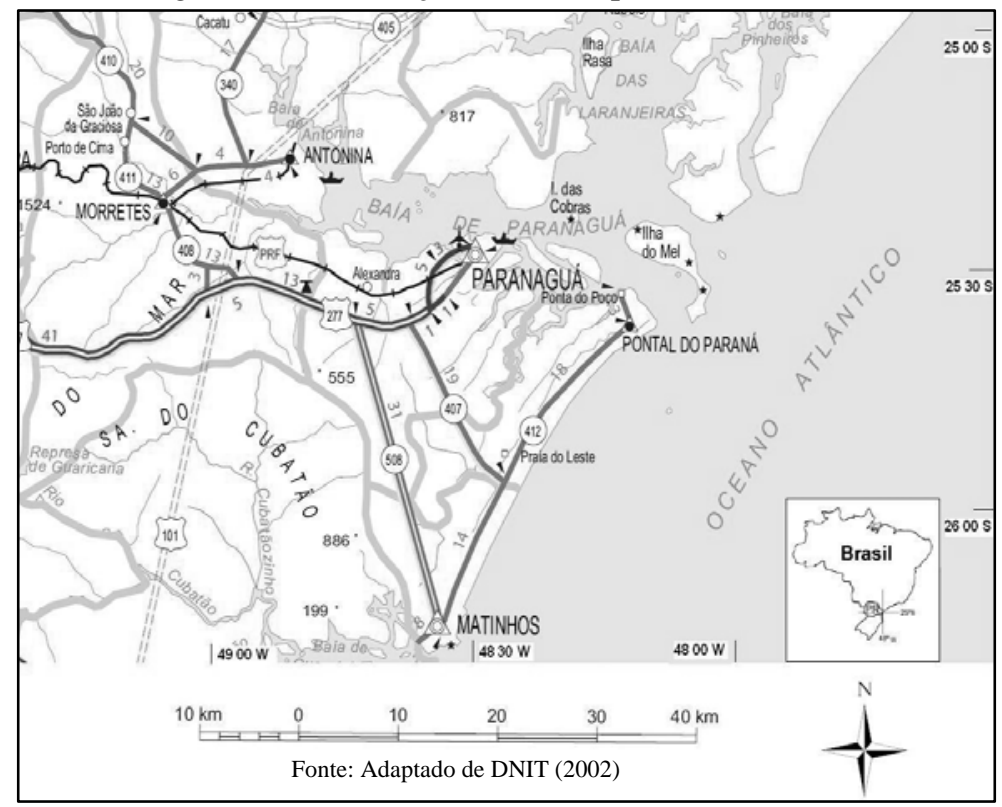

A Ilha do Mel é margeada pelos Canais Norte e Sueste e pelo Canal da Galheta ao Sul, na proximidade com Pontal do Paraná. Este último é o acesso dos navios em direção ao Porto de Paranaguá.

O relevo e a vegetação da Ilha do Mel proporcionaram a formação de 13 praias, são elas: Encantadas ou Prainha, Praia de Fora, Praia do Miguel, Praia Grande, Praia do Farol, Praia da Fortaleza, Praia do Farol do Cassual, Praia da 
Ponta do Hospital, Praia da Ponta Oeste/ Coroazinha, Praia do Cedro, Praia do Limoeiro, Praia Nova Brasília e Praia do Belo, conforme ilustra a Figura 2 (SEMA, 2004).

Os experimentos foram executados mais especificamente no esporão arenoso compreendido entre a Ponta do Farol das Conchas e o Istmo da Ilha do Mel. Segundo GIANNINI et al (2004), a intensificação do processo erosivo no Istmo de Nova Brasília durante a década de 1990 foi simultânea à formação de um esporão arenoso ancorado na ponta do Farol.

Figura 2 - A Ilha do Mel e sua situação no Litoral Paranaense.

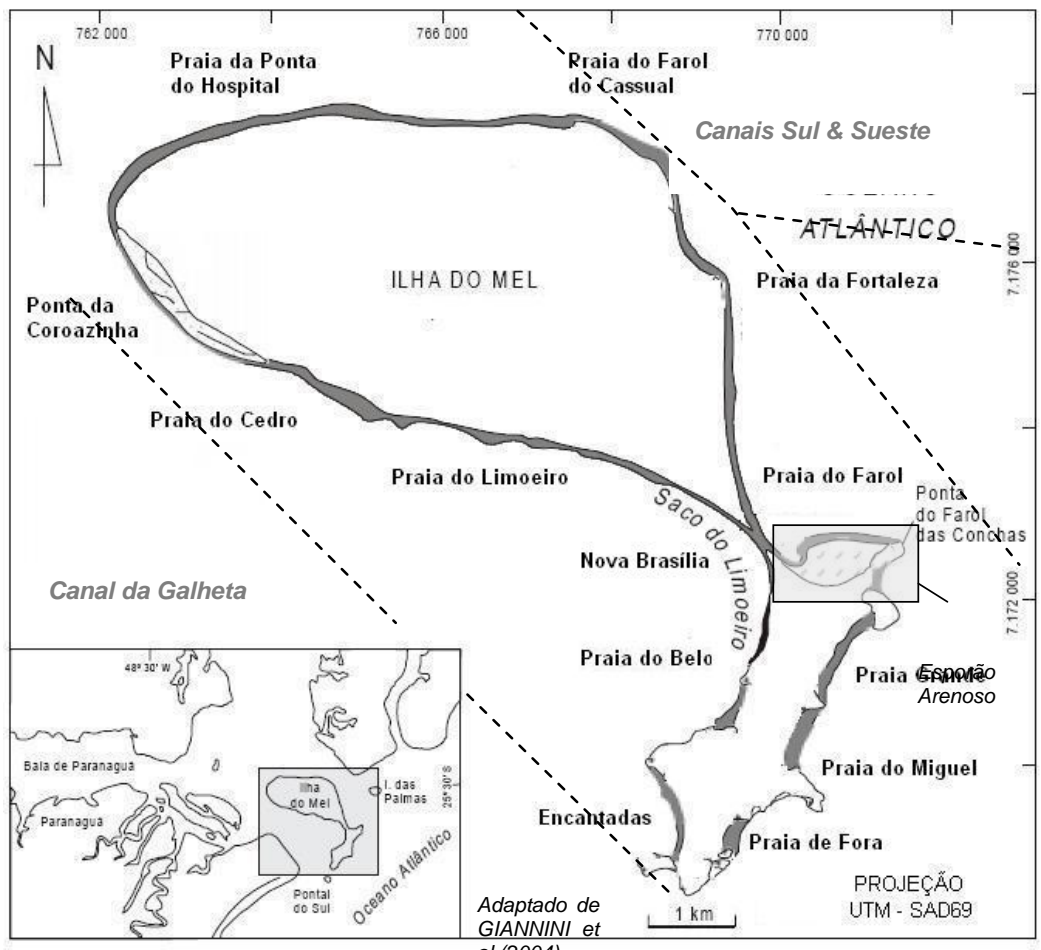

\section{METODOLOGIA}

Os levantamentos geodésicos foram efetuados ao longo de todo esporão arenoso, porém, para os testes de avaliação entre os métodos de posicionamento optou-se por adotar um pequeno trecho do esporão, doravante denominado Área Teste. Este trecho compreende aproximadamente um retângulo de dimensões 57 m x 32 m situado na parte oeste do esporão e apresenta as maiores variações relativas em altitudes. 
Os equipamentos utilizados no rastreio foram dois pares de receptores GPS de dupla frequência. Um par de receptor modelo Ashtech Z12 foi designado aos posicionamentos Absoluto Cinemático, Relativo Cinemático e DGPS. O posicionamento pelo método RTK ficou a cargo do receptor modelo Leica 1200, conforme descrito no Quadro 1.

Quadro 1 - Métodos de posicionamento efetuado com seu respectivo equipamento.

\begin{tabular}{|c|c|}
\hline $\begin{array}{c}\text { MÉTODO DE } \\
\text { POSICIONAMENTO }\end{array}$ & $\begin{array}{c}\text { EQUIPAMENTO } \\
\text { NA ESTAÇÃo } \\
\text { MÓVEL }\end{array}$ \\
\hline Absoluto Cinemático & Ashtech Z12 \\
\hline Relativo Cinemático & Ashtech Z12 \\
\hline DGPS & Ashtech Z12 \\
\hline RTK & Leica 1200 \\
\hline
\end{tabular}

Visando obter um único caminhamento no rastreio da estação móvel, um dispositivo foi idealizado de tal forma que fosse permitido montar num mesmo bastão as duas antenas GPS. Elas encontram-se excêntricas a 20 cm deste bastão, conforme indicado na Figura 3.

Figura 3 - Antenas GPS em um único bastão.

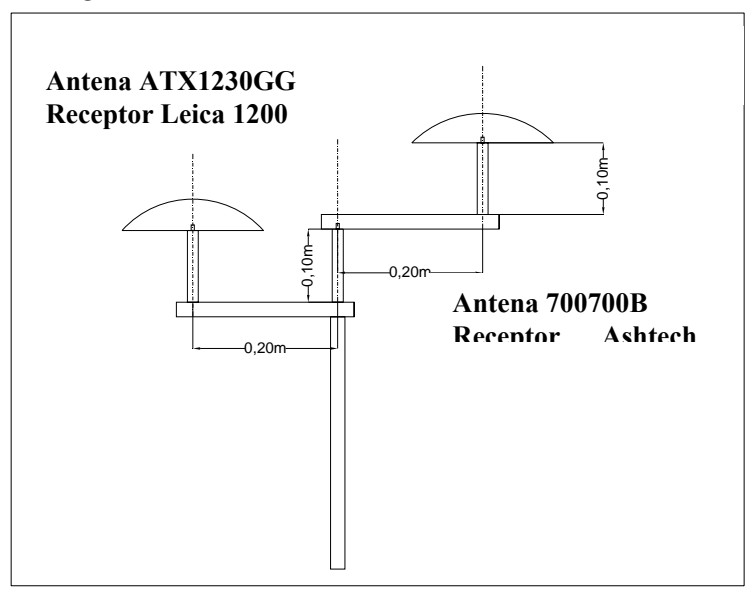

Pelo fato do rastreio operar com dois levantamentos diferenciais realizados simultaneamente (RTK e DGPS), teve-se a necessidade de utilizar duas estações de referência , cada uma delas comportou um equipamento incumbido de enviar suas respectivas correções diferenciais para os dois receptores da estação móvel integrada. As estações de referência foram alocadas estrategicamente nas proximidades da área levantada, formando uma linha de base média de $700 \mathrm{~m}$ com a estação móvel. 
O Quadro 2 ilustra as coordenadas geodésicas das estações de referência com seus respectivos desvios padrão.

Quadro 2 - Coordenadas Geodésicas das Estações de Referência.

\begin{tabular}{|c|c|c|c|c|c|c|c|}
\hline $\begin{array}{c}\text { Estaçã } \\
\mathbf{0}\end{array}$ & Latitude (S) & $\sigma_{(\mathbf{m})}$ & Longitude (W) & $\sigma_{(\mathbf{m})}$ & $\begin{array}{c}\text { Altitude } \\
\text { Elip. (m) }\end{array}$ & $\sigma_{\mathbf{( m )}}$ & $\begin{array}{l}\text { Sistema de } \\
\text { Referênci } \\
\mathbf{a}\end{array}$ \\
\hline CASA & $25^{\circ} 32^{\prime} 27,94866^{\prime \prime}$ & 0,005 & $\begin{array}{c}48^{\circ} 18^{\prime} \\
17,20718^{\prime \prime}\end{array}$ & 0,006 & 2,831 & 0,015 & $\begin{array}{c}\text { SIRGAS } \\
2000\end{array}$ \\
\hline CAS1 & $25^{\circ} 32^{\prime} 28,01589^{\prime \prime}$ & 0,005 & $\begin{array}{c}48^{\circ} 18^{\prime} \\
17,10608^{\prime \prime}\end{array}$ & 0,006 & 2,832 & 0,015 & $\begin{array}{c}\text { SIRGAS } \\
2000\end{array}$ \\
\hline
\end{tabular}

A proposta para análise comparativa das coordenadas obtidas pelos diferentes métodos de posicionamento consiste em considerar como padrão o grupo de coordenadas geodésicas provenientes do MRC, obtidas no pós-processamento dos dados brutos no software Ashtech Solutions. Em seguida as coordenadas oriundas dos demais métodos (MAC: dados brutos; DGPS e RTK: dados processados em tempo real) serão subtraídas das coordenadas consideradas como padrão, podendo dessa forma avaliar a acurácia atingida para cada método de posicionamento analisado.

Conforme abordado anteriormente, o levantamento realizado na Área Teste foi efetuado com as duas antenas montadas em um único bastão conforme ilustra a Figura 3. Dessa forma, apenas um caminhamento foi realizado, porém, cada antena descreveu sua própria trajetória de pontos coletados.

Para que as coordenadas pudessem ter sido comparadas foi preciso concentrálas em uma única trajetória, para isso, efetuou-se a correção dos off-sets, visto que as antenas estavam excêntricas a $20 \mathrm{~cm}$ do bastão. Na correção dos off-sets utilizouse uma rotina desenvolvida no software Matlab que realiza o deslocamento das coordenadas (convertidas para o sistema UTM) oriundas do rastreio com o RTK do eixo 1 para o eixo 3, dos demais métodos rastreados (MAC, MRC, DGPS), conforme ilustra a Figura 4.

A antena A representa o modelo ATX1230GG utilizado no GPS Leica 1200 para o levantamento RTK, a antena B refere-se ao modelo 700700B da Ashtech.

Após uma análise de quadrante, o Azimute $\boldsymbol{A z}$ da direção $\boldsymbol{A B}$ pode ser determinado a partir da Equação:

$$
A z_{A_{i} \rightarrow B_{i}}=\operatorname{Tan}^{-1}\left(\frac{E_{B_{i}}-E_{A_{i}}}{N_{B_{i}}-N_{A_{i}}}\right) .
$$

Onde:

$E_{A_{i}}, N_{A_{i}}=$ Coordenadas UTM de $A$ no intervalo de gravação $i$; 
$E_{B_{i}}, N_{B_{i}}=$ Coordenadas UTM de $\boldsymbol{B}$ no intervalo de gravação $i$.

Figura 4 - Vistas frontal e superior das antenas e descrição dos eixos.

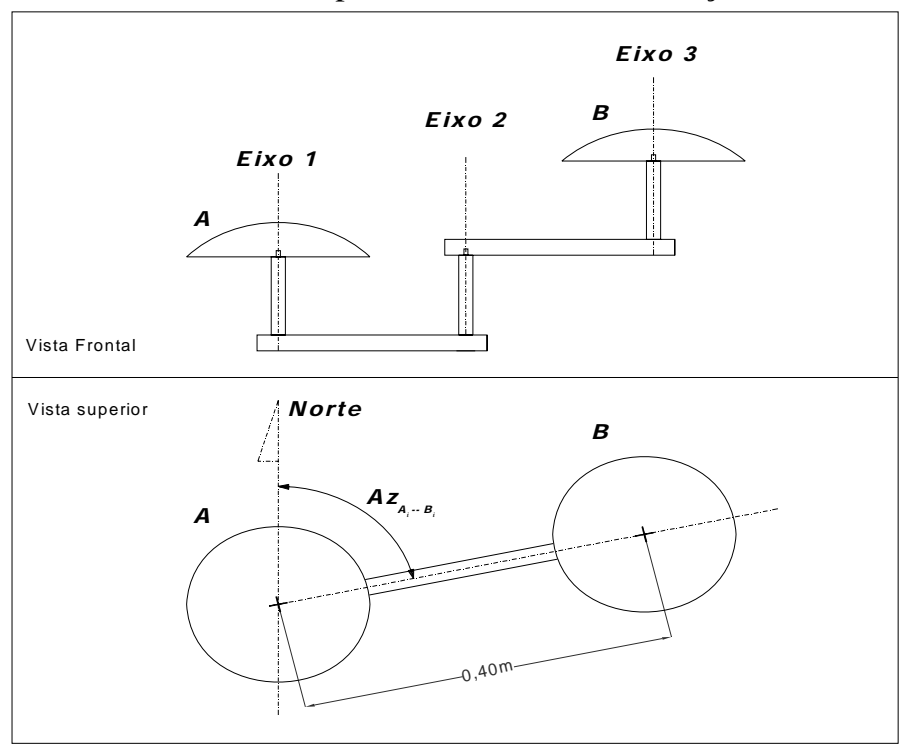

De posse do valor da linha de base que une as duas antenas $(0,40 \mathrm{~m})$ procedese realizando a correção dos off-sets entre os eixos 1 e 3 a partir das Equações:

$$
\begin{aligned}
& E_{A_{i}}^{c}=E_{A_{i}}+0,4 \operatorname{sen}\left(A z_{A_{i} \rightarrow B_{i}}\right), \\
& N_{A_{i}}^{c}=N_{A_{i}}+0,4 \cos \left(A z_{A_{i} \rightarrow B_{i}}\right) .
\end{aligned}
$$

Onde:

$E_{A_{i}}^{c}, N_{A_{i}}^{c}=$ Coordenadas UTM corrigidas no intervalo de gravação $i$.

O levantamento originou um total de 366 pontos rastreados para cada método de posicionamento separadamente, coletados com um intervalo de gravação de 3 segundos, o que totaliza uma quantidade de 1464 pontos.

A Figura 5 ilustra o esporão arenoso destacando a Área Teste com o caminhamento realizado pela estação móvel durante o levantamento. 
Figura 5 - Esporão Arenoso e Área Teste rastreada.

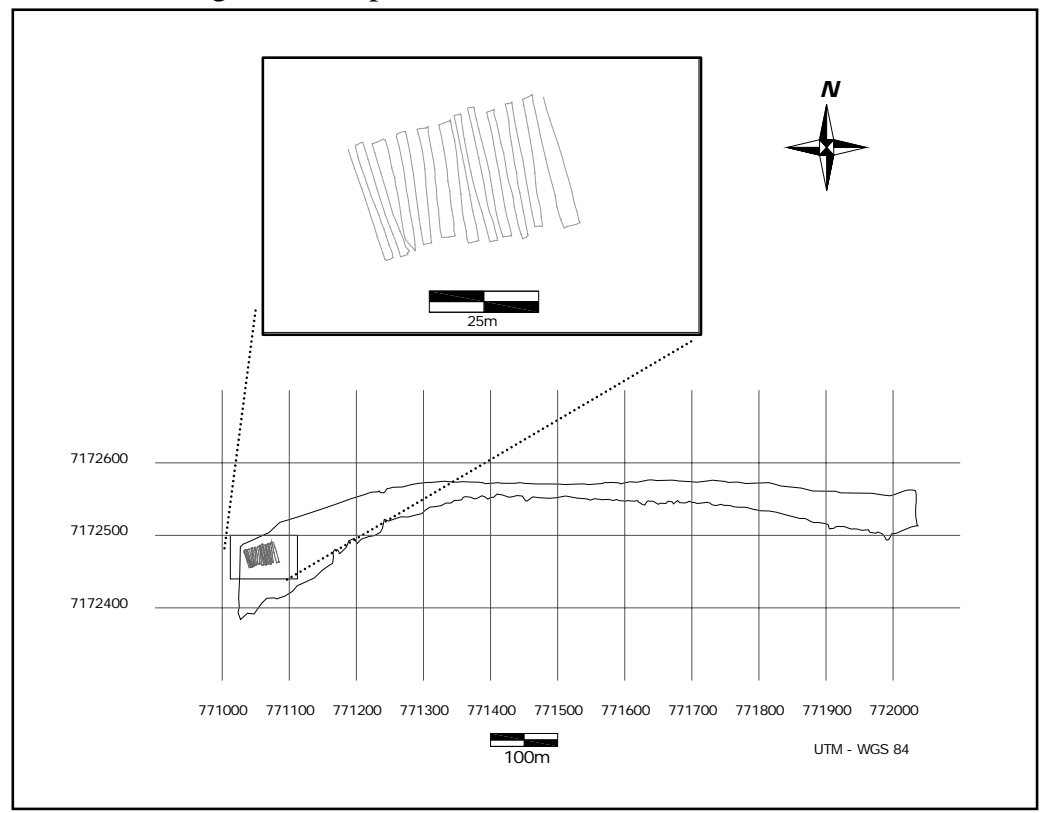

\section{ANÁLISES DOS RESULTADOS}

Após o cálculo das diferenças entre cada componente das coordenadas planas oriundas dos três métodos (MAC, RTK e DGPS) com sua homóloga no grupo de coordenadas consideradas como padrão (MRC) obtiveram-se as seguintes estatísticas conforme ilustra a Tabela 1.

Tabela 1 - Valor absoluto das máximas e mínimas diferenças entre as componentes das coordenadas e o Erro Médio Quadrático (EMQ).

\begin{tabular}{c|c|c|c|c|c|c|c|c|c}
\hline \multirow{2}{*}{$\begin{array}{c}\text { Método de } \\
\text { Posicionamento }\end{array}$} & \multicolumn{9}{|c|}{ 366 Coordenadas geradas (metros) } \\
\cline { 2 - 11 } & \multicolumn{3}{|c|}{$\Delta \mathbf{N}$} & \multicolumn{3}{c}{$\Delta \mathbf{E}$} & \multicolumn{3}{c}{$\Delta \mathbf{b}$} \\
\hline & Máx & Mín & EMQ & Máx & Mín & EMQ & Máx & Mín & EMQ \\
\hline RTK & 0,400 & 0,000 & 0,003 & 0,406 & 0,000 & 0,007 & 0,210 & 0,065 & 0,149 \\
\hline DGPS & 0,376 & 0,000 & 0,175 & 0,425 & 0,000 & 0,151 & 35,036 & 0,008 & 5,824 \\
\hline MAC & 0,244 & 0,195 & 0,220 & 1,710 & 1,377 & 1,553 & 10,907 & 10,742 & 10,868 \\
\hline
\end{tabular}

Analisando os resultados referentes ao EMQ, verifica-se que os valores obtidos estão dentro do esperado. O RTK apresenta os resultados mais satisfatórios 
0,3 cm para a componente Norte, 0,7 cm para a componente Este e 14,9 cm para a Altura Geométrica $\mathbf{h}$. As menores diferenças calculadas indicam a maior proximidade da solução considerada como padrão.

Apesar dos EMQ's referentes ao MAC possuírem os maiores valores entre os demais, as diferenças absolutas referente ao DGPS são as mais discrepantes entre os três métodos, com valores variando de 0,008 m a 35,036 m na Altura Geométrica. A discrepância dos valores referentes ao DGPS, principalmente na Altura Geométrica, provavelmente foi originada a partir de alguma falha no envio das correções em tempo real. Vale ressaltar que os dados que geraram os pontos do DGPS e MAC são oriundos da mesma antena, o que não justifica tamanho descompasso entre eles.

Os intervalos de variação das diferenças calculadas para cada componente dos pontos rastreados para os três métodos podem ser visualizados graficamente conforme ilustram as Figuras 6 a 8.

Figura 6 - Gráfico de diferenças das componentes para o MAC.

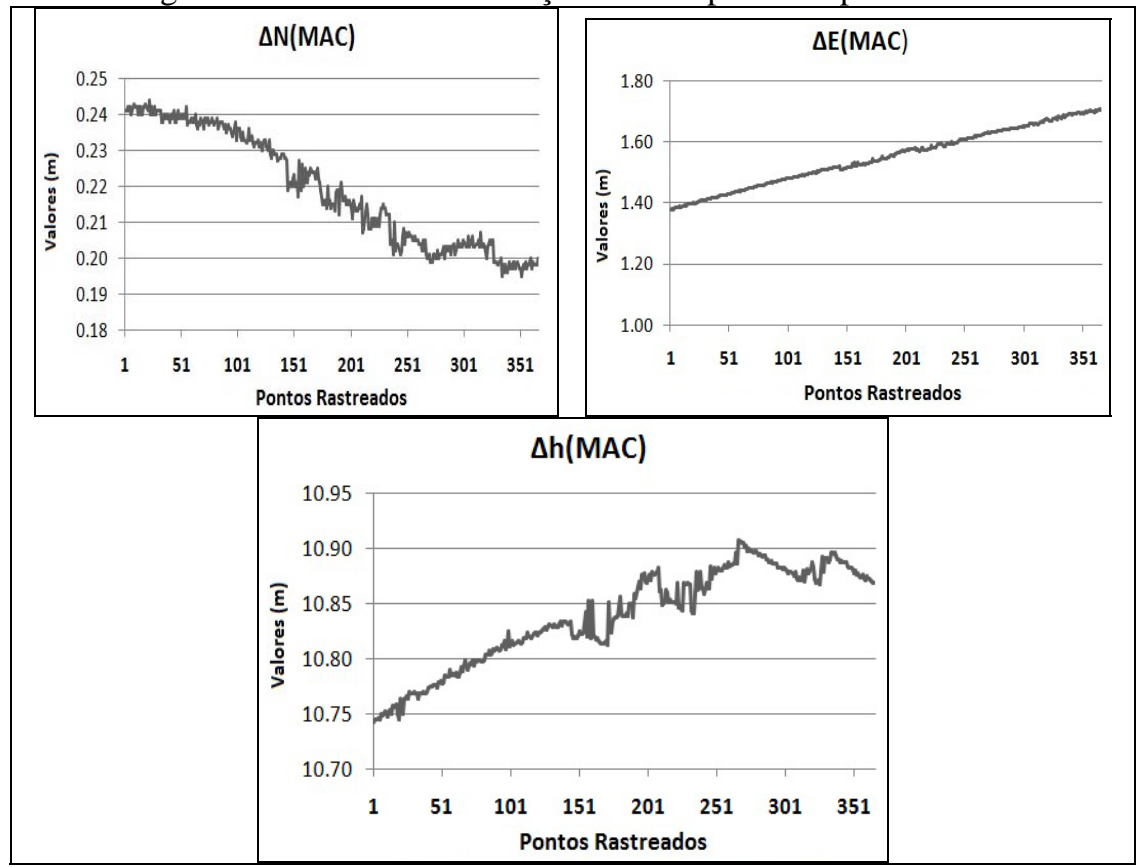

Bol. Ciênc. Geod., sec. Artigos, Curitiba, v. 17, nº 1, p.23-36, jan-mar, 2011. 
Figura 7 - Gráfico de diferenças das componentes para o DGPS.

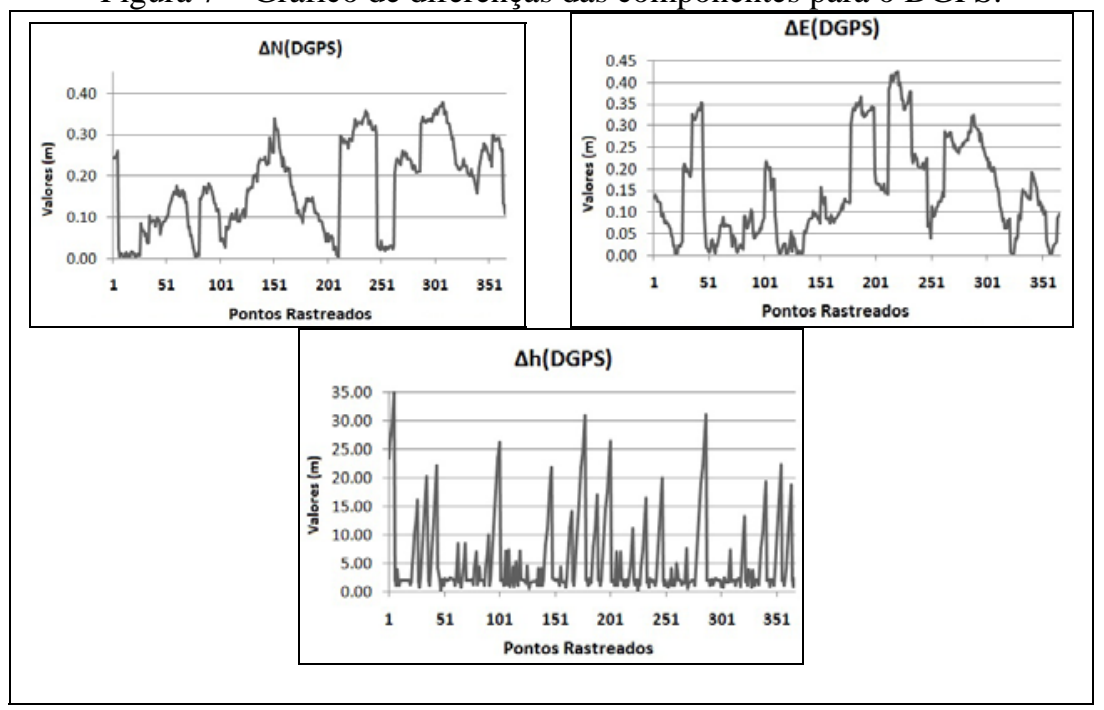

Figura 8 - Gráfico de diferenças das componentes para o RTK.

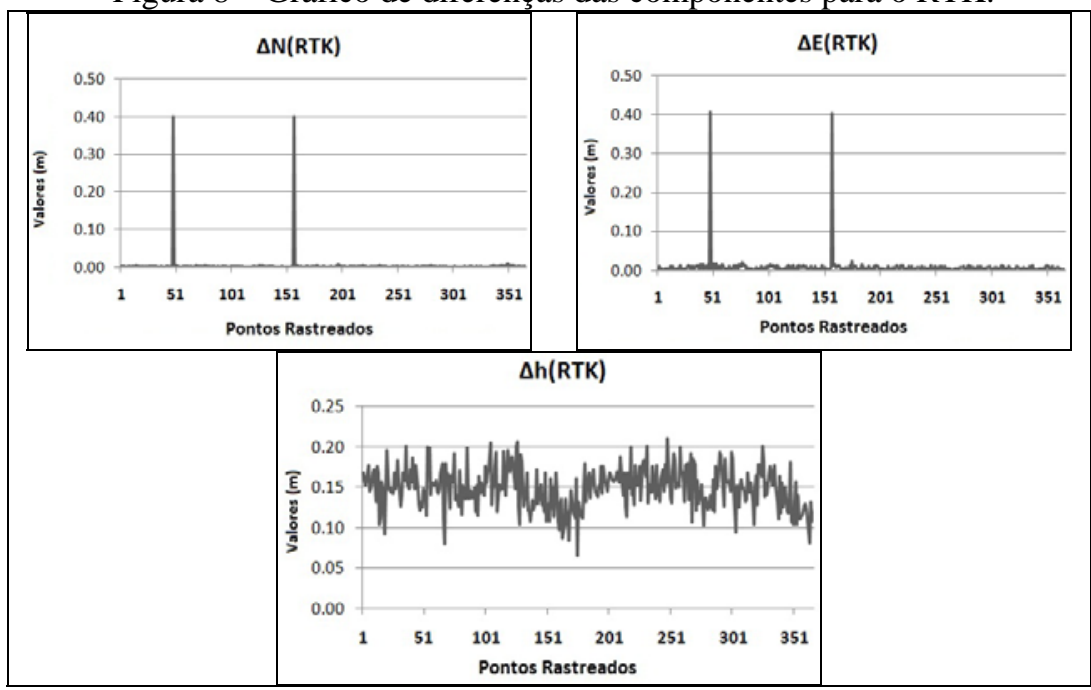

Analisando a Figura 6 verifica-se graficamente que ao longo do rastreio as variações das componentes Este e Altura Geométrica h são crescentes e a componente Norte segue decrescente. Porém, o intervalo de variação das três componentes é relativamente pequeno. Esse intervalo de variação pode ser 
quantificado realizando a diferença entre os valores máximos e míninos do MAC vistos anteriormente na Tabela 1 . Os valores resultantes são de 4,9 cm, 33,3 cm e $16,5 \mathrm{~cm}$ para $\mathbf{N}, \mathbf{E}$ e $\mathbf{h}$, respectivamente.

Os gráficos das componentes do DGPS são caracterizados pelas inúmeras variações ao longo do rastreio, conforme pôde ser visto na Figura 7. Dentre os métodos verificados o DGPS é o que apresentou as maiores variações para as três componentes analisadas, sendo a Altura Geométrica $\mathbf{h}$ a mais degradada entre as demais, variando num intervalo de 35,028 m.

Analisando a Figura 8, verifica-se que as soluções oriundas do RTK apresentam uma melhor qualidade, conforme já era esperado. As diferenças calculadas nas componentes Norte e Este são mínimas, pois suas linhas encontramse, em praticamente todo o rastreio, adjacentes ao eixo das abscissas, indicando valores próximos a zero (exceto dois picos nos gráficos provavelmente resultantes de erros no envio das correções). A componente vertical também apresenta uma variação satisfatória oscilando em torno de $15 \mathrm{~cm}$.

Apesar da solução MAC apresentar resultados numericamente desfavoráveis (maiores EMQ's, vide Tabela 1), observa-se na Figura 6 que os gráficos das variações estão deslocados ao longo do eixo das ordenadas. Esse deslocamento também é verificado analisando-se a Tabela 2. Percebe-se que as diferenças das componentes em cada ponto são da mesma ordem de grandeza e a média desses valores é de 0,219 m, 1,549 m e 10,838 m para N, E e h respectivamente.

Tabela 2 - Diferenças e correções das componentes do MAC (m).

\begin{tabular}{c|c|c|c|c|c|c}
\hline & $\mathbf{\Delta N}(\mathbf{M A C})$ & $\mathbf{\Delta E}(\mathbf{M A C})$ & $\mathbf{\Delta h}(\mathbf{M A C})$ & $\mathbf{\Delta N - \mathbf { 0 , 2 1 9 }}$ & $\mathbf{\Delta E}-\mathbf{1 , 5 4 9}$ & $\mathbf{\Delta h - 1 0 , 8 3 8}$ \\
\hline $\mathbf{1}$ & 0,241 & 1,377 & 10,742 & 0,022 & 0,172 & 0,096 \\
\hline $\mathbf{2}$ & 0,241 & 1,381 & 10,744 & 0,022 & 0,168 & 0,094 \\
\hline $\mathbf{3}$ & 0,242 & 1,379 & 10,744 & 0,023 & 0,170 & 0,094 \\
\hline $\mathbf{4}$ & 0,241 & 1,381 & 10,746 & 0,022 & 0,168 & 0,092 \\
\hline $\mathbf{5}$ & 0,242 & 1,384 & 10,745 & 0,023 & 0,165 & 0,093 \\
\hline $\mathbf{6}$ & 0,240 & 1,385 & 10,749 & 0,021 & 0,164 & 0,089 \\
\hline $\mathbf{7}$ & 0,241 & 1,387 & 10,748 & 0,022 & 0,162 & 0,090 \\
\hline $\mathbf{8}$ & 0,242 & 1,386 & 10,749 & 0,023 & 0,163 & 0,089 \\
\hline $\mathbf{9}$ & 0,243 & 1,388 & 10,752 & 0,024 & 0,161 & 0,086 \\
\hline $\mathbf{1 0}$ & 0,242 & 1,387 & 10,750 & 0,023 & 0,162 & 0,088 \\
\hline $\mathbf{.}$ & & & & & & \\
\hline $\mathbf{.}$ & & & & & & \\
\hline $\mathbf{3 6 5}$ & 0,198 & 1,710 & 10,869 & 0,021 & 0,161 & 0,031 \\
\hline $\mathbf{3 6 6}$ & 0,200 & 1,706 & 10,869 & 0,019 & 0,157 & 0,031 \\
\hline & & & & & & \\
\hline Média & $\mathbf{0 , 2 1 9}$ & $\mathbf{1 , 5 4 9}$ & $\mathbf{1 0 , 8 3 8}$ & - & - & - \\
\hline
\end{tabular}

Ao ser realizada uma subtração do valor médio verificado das respectivas componentes em cada ponto do rastreio, buscou-se aproximar o gráfico ao eixo das abscissas conforme ilustra a Figura 9. 
Figura 9 - Gráfico de diferenças das componentes para o MAC subtraído do valor médio calculado.

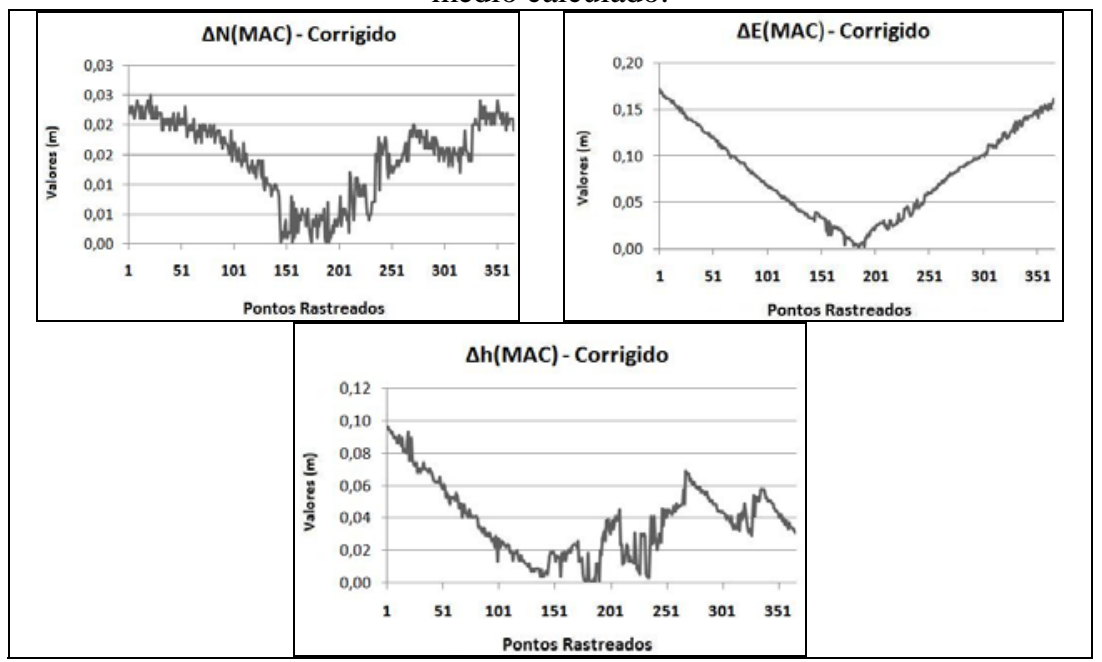

Com a subtração realizada há uma melhora no resultado final, onde as coordenadas do MAC corrigidas aumentam o grau de proximidade das coordenadas consideradas como padrão (MRC), resultando assim os EMQ's de 0,014 m, 0,082 m e 0,038 m para $\mathbf{N}$, $\mathbf{E}$ e $\mathbf{h}$ respectivamente.

\section{CONSIDERAÇÕES FINAIS}

O nível de acurácia alcançado pelo método RTK possibilita sua utilização em diversas aplicações GPS que exija coordenadas precisas em tempo real. Porém para levantamentos desse caráter onde geralmente as precisões almejadas encontram-se aquém das atingidas por esse método, ele não se torna o mais indicado, devido à alta relação custo/benefício.

O método de posicionamento DGPS apesar de ter apresentado resultados numericamente satisfatórios no posicionamento horizontal, com os EMQ's de 0,175 m e 0,151 m em Norte e Este, respectivamente, foi caracterizado pelas instáveis variações das componentes ao longo do rastreio. No posicionamento vertical o DGPS deixou a desejar, apresentando alturas geométricas com qualidades inferiores às esperadas, fato esse que pode ter sido decorrente de erros no envio das correções.

As coordenadas oriundas do MAC apresentaram resultados dentro do esperado com os EMQ's de 0,220 m, 1,553 m e 10,868 m para N, E e h, respectivamente. Outrora, esses números foram melhorados após realizada a subtração do valor médio das diferenças para cada componente, obtendo para os EMQ’s, os 
respectivos valores em $\mathbf{N}$, E e $\mathbf{h}$ de $0,014 \mathrm{~m}, 0,082 \mathrm{~m}$ e 0,038 $\mathrm{m}$, aumentando assim seu grau de proximidade para as coordenadas consideradas como padrão (MRC).

De acordo com os resultados obtidos nos levantamentos verificou-se que o nível de acurácia atingido por todos os métodos (com exceção do posicionamento vertical do DGPS) estão dentro das suas respectivas preconizadas pela literatura nas condições as quais foram efetuados.

\section{AGRADECIMENTOS}

Os autores desejam expressar seus agradecimentos a todos que contribuíram com as atividades de campo, ao Laboratório de Ciências Geodésicas da UFPR e a CAPES.

\section{REFERÊNCIAS BIBLIOGRÁFICAS}

DIVIS, D.A. AS: Going the way of the dinosaur. Washington, 2000, pp.16-19. GPS World, v.11, n.6.

DNIT. Departamento Nacional de Infra-estrutura de Transportes. Mapa Rodoviário do Paraná, 2002.

GIANNINI, P. C. F; ANGULO R. J.; SOUZA, M. C. de; KOGUT, J. S.; DELAI, M. S. A Erosão na Costa Leste da Ilha do Mel, Baía de Paranaguá, Estado do Paraná: Modelo Baseado na Distribuição Espacial de Formas Deposicionais e Propriedades Sedimentológicas. Curitiba, 2004, pp. 231-242. Revista Brasileira de Geociências, v 34.

HOFMANN-WELLENHOF, B.; LICHTENEGGER, J.; COLLINS, J. GPS: Theory and Practice. New York, 1994, 326p. Springer Verlag Wien, $3^{\text {rd }}$ ed.

IBAMA. Erosão e progradação no litoral brasileiro. Brasília, 2006, 475p. Livro Ministério do Meio Ambiente. Organização: Dieter Muehe.

MONICO, J. F. G. Posicionamento pelo GNSS: Descrição, Fundamentos e aplicações. São Paulo, 2008, 476p. Editora UNESP, $2^{\mathrm{a}}$ ed.

KRUEGER, C. P. Investigações Sobre Aplicações de Alta Precisão do GPS no Âmbito Marinho. Curitiba, 1996, 267p, tese de doutorado em Ciências Geodésicas.

SEEBER, G. Satellite Geodesy: Foundations, Methods and Aplications. BerlinNew York, 2003, 589p. Walter de Gruyter. $2^{\text {nd }}$ revised edition.

SEMA. Secretaria de Estado do Meio Ambiente e Recursos Hídricos. Plano de Controle Ambiental e Uso do Solo da Ilha do Mel. Curitiba, 2004, CD ROM.

(Recebido em março de 2010. Aceito em janeiro de 2.011.) 